\title{
A UTILIZAÇÃO DO GEOPROCESSAMENTO EM CAMPANHAS DE VACINAÇÃO CONTRA A RAIVA DE CÃES E GATOS
}

\author{
APPLICATIONS OF GEOPROCESSING IN RABIES VACCINATION CAMPAIGNS IN \\ CATS AND DOGS
}

\author{
A. P. ALMEIDA ${ }^{1 *}$, B. B. BRANCALION ${ }^{1}$, C. M. RIBEIRO ${ }^{1}$, E. B. DE PALMA ${ }^{1}$, F. A. FIORANI ${ }^{1}$, \\ L. S. ROLIM ${ }^{1}$, J. R. MODOLO ${ }^{1}$, C. VICTÓRIA ${ }^{1}$
}

\section{RESUMO}

Aliar saúde humana, saúde animal e saúde ambiental em torno da estratégia "Um mundo, uma saúde" não é uma tarefa fácil. A análise espacial (ambiente) em saúde é um aspecto fundamental na epidemiologia. Dentre as várias técnicas utilizadas para a análise espacial dos serviços de saúde, pode-se citar o geoprocessamento, que envolve etapas de coleta, tratamento e exibição de informações indexadas geograficamente. $\mathrm{O}$ objetivo deste trabalho é demonstrar que o geoprocessamento pode ser uma ferramenta útil no planejamento, execução, avaliação e elaboração de relatórios de campanhas de vacinação animal. Os dados utilizados são provenientes da $43^{\mathrm{a}}$ Campanha de vacinação contra a raiva de cães e gatos de Botucatu/SP. Na fase de planejamento e execução utilizaram-se os pontos georreferenciados pela prefeitura; nas fases de avaliação e elaboração do relatório, os pontos utilizados foram aqueles georreferenciados no transcorrer da campanha com GPS móvel (Garmin Etrex Venture ${ }^{\circledR}$ ), relativos aos locais onde estavam instalados os postos de vacinação temporários. Para a confecção dos mapas, utilizou-se o ArcGIS $10.1^{\circledR}$ da empresa Esri. Durante o planejamento e execução, a utilização dos mapas pôde orientar a distribuição dos postos, como nos novos loteamentos, com base na área de abrangência de 500 metros. Além disso, pôde facilitar a determinação dos postos transitórios e dos permanentes, e também dos pontos de apoio, tanto para a população como para os recursos humanos envolvidos na Campanha. Nas fases de análise e elaboração do relatório, o qual ficou extremamente rico com os mapas, pôde-se visualizar e definir quais regiões do município têm maior densidade populacional de cães ou gatos. A análise espacial não se resume apenas ao mapeamento dos eventos, pois embora um mapa tenha um aspecto estático, ele tem a capacidade de refletir sinteticamente todo o complexo processo que é uma campanha antirrábica realizada em um município.

PALAVRAS-CHAVE: PLANEJAMENTO. ANTIRRÁBICA. ANÁLISE ESPACIAL

ÁREA TEMÁTICA: Planejamento em Saúde Animal e Saúde Pública Veterinária.

\footnotetext{
${ }^{1}$ Faculdade de Medicina Veterinária e Zootecnia da Universidade Estadual Paulista (UNESP) - Campus de Botucatu * arthurpombo_mv@hotmail.com
} 